\title{
POTENCIAL MOTIVADOR DO TRABALHO: TRADUÇÃO E ADAPTAÇÃO CULTURAL DO INSTRUMENTO DE HACKMAN E OLDHAM
}

\section{MOTIVATING POTENTIAL SCORE: TRANSLATION AND CULTURAL ADAPTATION OF THE HACKMAN AND OLDHAM'S INSTRUMENT}

\author{
Bruno Pedroso* brunops3@brturbo.com.br \\ Luiz Alberto Pilatti* lapilatti@utfpr.edu.br \\ Celso Bilynkievycz dos Santos* bilynkievycz@globo.com \\ Guataçara dos Santos Junior* bilynkievycz@globo.com \\ * Universidade Tecnológica Federal do Paraná
}

\begin{abstract}
Resumo: O objetivo do presente estudo foi traduzir e adaptar culturalmente 0 instrumento de avaliação do Potencial Motivador do Trabalho proposto por Hackman e Oldham (1974) para a língua portuguesa. O método utilizado envolveu uma equipe multidisciplinar entre pesquisadores e profissionais da área de linguística, de forma que o instrumento fora traduzido, submetido à correção ortográfica, adaptado para a cultura local e, por fim, conferido com a sua versão original. Este estudo resultou em um questionário composto por 15 questões fechadas, com respostas baseadas em uma escala de Likert de sete alternativas onde as características psicométricas do instrumento original foram preservadas. Os resultados são expressos na escala geométrica original do instrumento (1 a 343) e também em uma escala centesimal ( 0 a 100) proposta nesse estudo. Conclui-se que os procedimentos utilizados na tradução e adaptação cultural do instrumento em exame minimizam a possibilidade de uma tradução equivocada, além de permitir que as aplicações do instrumento proposto possam ser comparadas com o instrumento em seu idioma vernáculo e também com outros instrumentos.
\end{abstract}

Palavras-chave: Qualidade de Vida no Trabalho. Potencial Motivador do Trabalho. Hackman e Oldham. Instrumento de avaliação. Adaptação cultural.

\begin{abstract}
This paper objectifies the translation and cultural adaptation for Portuguese language of the instrument of evaluation of the Motivating Potential Score proposed by Hackman and Oldham (1974). The used method involved a multidisciplinary team among researchers and professionals of the linguistics area. The instrument was translated, submitted to the spell checker, adapted for the local culture and, finally, checked with its original version. This study resulted in a questionnaire composed by 15 multiple choice questions, with answers based on a Likert's scale of seven options where the psychometric characteristics of the original instrument were preserved. The outcomes are expressed in the original geometric scale of the instrument (1 to 343) and also in a centesimal scale (0 to 100) proposed in this study. It concludes that the procedures used in translation and cultural adaptation of this instrument minimize the possibility of a mistaken translation, besides allowing that the applications of the proposed instrument can be compared with the instrument in its original language and also with other instruments.
\end{abstract}

Keywords: Quality of Work Life. Motivating Potential Score. Hackman and Oldham. Instrument of evaluation. Cross-cultural adaptation. 


\section{INTRODUÇÃO}

A preocupação com a qualidade de vida no ambiente laboral tem sua progênie na Revolução Industrial. Reivindicações originadas de trabalhadores crescentemente organizados, no curso de uma história que nasceu nas "Usinas de Satã", fez com que o trabalho se tornasse mais humanizado ou, principalmente nas fases iniciais, menos desumanizado. A transmutação ocorreu de forma lenta, forjada por pequenas conquistas advindas de difíceis entraves, quase sempre acompanhado de um aparato legal.

O trabalho ocupa uma parcela significativa da vida das pessoas. Fato esse que justifica as intervenções na vida pessoal do trabalhador. Ainda que permeados por variáveis muito semelhantes e grande inter-relação, os conceitos de qualidade de vida e qualidade de vida no trabalho apresentam uma distinção que vem se acentuando com a vida societária que ganhou muito em complexidade. A sobreposição entre a qualidade de vida e o trabalho, uma vez que a qualidade de vida é multidimensional, demonstra que as vivências no ambiente laboral influenciam de forma direta e significativa na qualidade de vida do trabalhador (TOLFO; PICCININI, 2001). O que, de fato, conduz ao questionamento se existe um índice mensurável sobre a influência do trabalho na qualidade de vida, ou o quanto o trabalho pode ser benéfico ou prejudicial para a vida de quem o realiza.

$\mathrm{Na}$ tentativa de mensurar o nível de motivação gerado pelo trabalho, Hackman e Oldham (1974) propõem um escore denominado "Potencial Motivador do Trabalho". O Potencial Motivador do Trabalho é parte integrante do instrumento Job Diagnostic Survey (Pesquisa de Diagnóstico do Trabalho) desenvolvido por Hackman e Oldham (1974). O Job Diagnostic Survey foi nomeado na comunidade científica brasileira como o "Modelo de Qualidade de Vida no Trabalho de Hackman e Oldham" (FERNANDES, 1996).

Ainda que datado de mais de três décadas, a utilização do instrumento de Hackman e Oldham prevalece na contemporaneidade, como pode ser observado nos estudos de Lawrence (2001), Gabris e Ihrke (2001), Friday e Friday (2003), LeeRoss (2005) e Todd e Kent (2006). Todavia, uma versão traduzida validada do referido instrumento para o idioma português é inexistente na literatura. 
Nessa perspectiva, o presente estudo tem como objetivo a tradução e adaptação cultural do instrumento para determinar o Potencial Motivador do Trabalho percebido pelos trabalhadores, proposto por Hackman e Oldham (1974), para o idioma português.

A tradução do instrumento de avaliação do Potencial Motivador do Trabalho fundamentou-se na necessidade de utilização de uma ferramenta que permita - de forma quantitativa - mensurar o quanto um trabalho pode proporcionar de motivação para aqueles que o executam. Portanto, busca-se através deste estudo a disponibilização, no idioma português, de um instrumento de rápido e fácil preenchimento e com características psicométricas satisfatórias. Adicionalmente é proposta uma escala alternativa para representar o escore do Potencial Motivador do Trabalho.

\section{POTENCIAL MOTIVADOR DO TRABALHO}

Com base nos estudos de Hackman e Oldham (1974; 1975), Chang Júnior e Albuquerque (2002) e Davis e Newstrom (2004), pode se afirmar que há três fatores que influenciam na motivação no ambiente laboral, denominados Estados Psicológicos Críticos: conhecimento e resultados do seu trabalho; responsabilidade percebida pelos resultados do seu trabalho e; significância percebida do seu trabalho.

Os Estados Psicológicos Críticos são processos individuais que não podem ser influenciados durante o gerenciamento do trabalho, portanto, é preciso determinar propriedades do trabalho que sejam passíveis de avaliação e mudança, e que possuam influência direta nos Estados Psicológicos Críticos. Estes recebem a denominação de Dimensões Essenciais do Trabalho (CHANG JÚNIOR; ALBUQUERQUE, 2002).

Há, também, fatores secundários que influenciam nas dimensões do trabalho e nos resultados, denominados Resultados Pessoais e do Trabalho: motivação interna ao trabalho; satisfação geral com o trabalho; satisfação com a sua produtividade e; absenteísmo e rotatividade. Por fim, existe a Necessidade de Crescimento Individual, que se correlaciona diretamente com as Dimensões 
Essenciais do Trabalho e os Resultados Pessoais e do Trabalho. Seguindo essa linha de raciocínio, Hackman e Oldham $(1974 ; 1975)$ propõem o seguinte modelo:

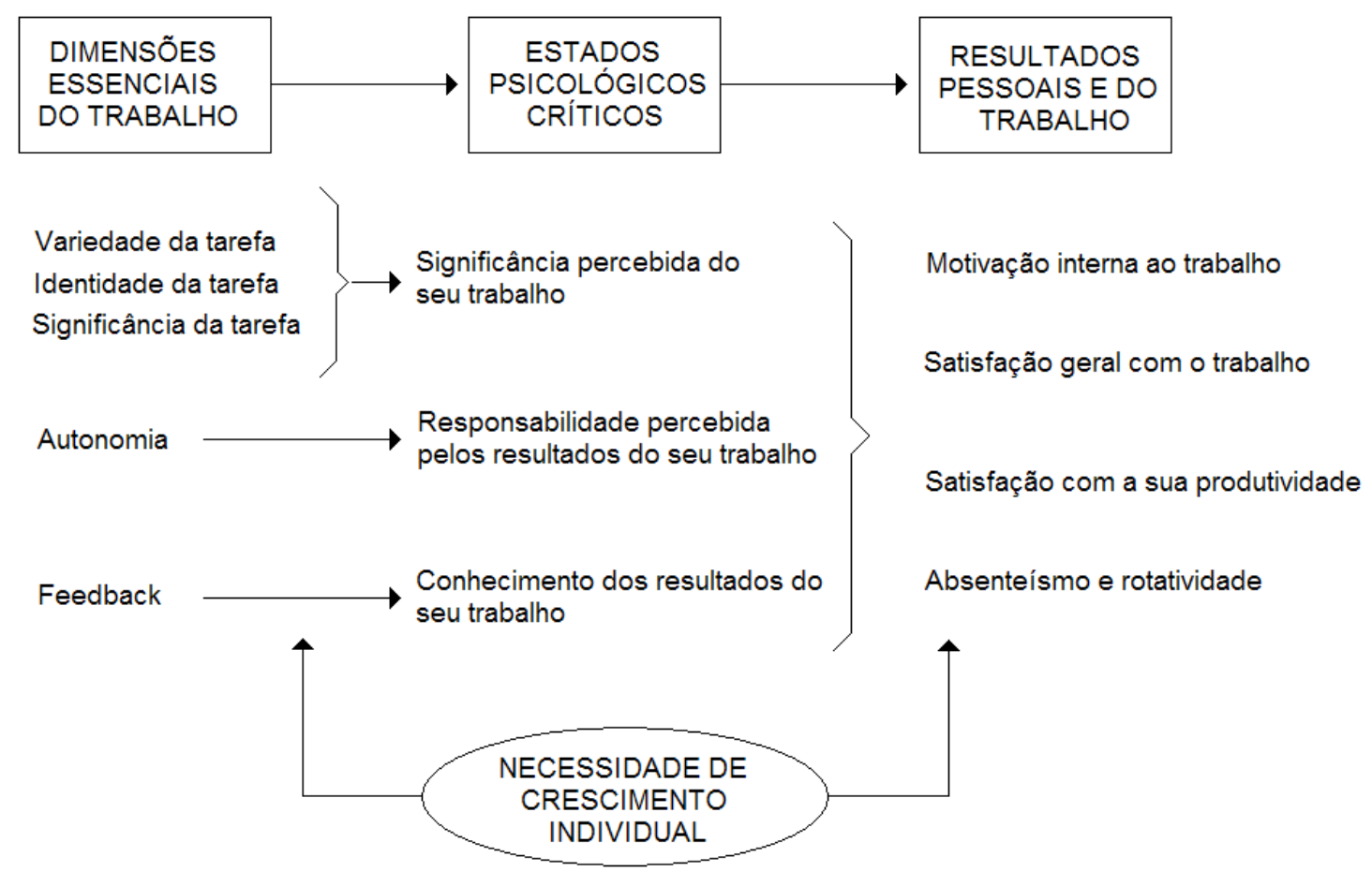

Figura 1: Modelo de Qualidade de vida no Trabalho de Hackman e Oldham Fonte: Adaptado de Hackman e Oldham (1974)

O instrumento para a determinação do Potencial Motivador do Trabalho avalia as propriedades motivacionais do trabalho, através 15 questões fechadas. As questões possuem enfoque nas cinco Dimensões Essenciais do Trabalho propostas por Hackman e Oldham: Variedade da Tarefa, Identidade da Tarefa, Significado da Tarefa, Autonomia, Feedback.

Dessa forma, o Potencial Motivador do Trabalho "indica o grau até o qual o trabalho é considerado Significativo, fomenta a Responsabilidade e promove o Conhecimento dos Resultados" (DAVIS; NEWSTROM, 2004, p. 154). É um instrumento com questões objetivas, com respostas dispostas em uma escala tipo Likert, de sete elementos. Na maioria dos casos, não demanda mais do que 10 minutos para seu preenchimento.

O cálculo desse escore está calçado na idéia de que "antes que um programa de enriquecimento de trabalho [Qualidade de Vida no Trabalho] tenha início, um empregador precisa estudar tarefas para avaliar quanto elas contêm variedade, identidade, significância, autonomia e feedback" (DAVIS; NEWSTROM, 2004, p. Revista Produção Online, v.10, n.3, p. 670-697, set., 2010 
154). Sob esse enfoque, ressalta-se a importância da existência de uma ferramenta para a determinação, através de uma abordagem quantitativa, do nível de motivação proporcionado pelo trabalho.

\section{MODELO DE HACKMAN E LAWLER}

O modelo proposto por Hackman e Oldham (1974) deriva de um estudo anterior realizado por Hackman e Lawler (1971). Neste estudo anterior, foi realizado um levantamento das características presentes no trabalho, de forma a estabelecer condições que motivam os trabalhadores. Os indivíduos tendem a apresentar uma satisfação pessoal significativa quando vivenciam no trabalho elevados índices de Variedade, Autonomia, Identidade da Tarefa e Feedback. Esses quatro fatores foram denominados de Dimensões Essenciais do Trabalho.

De acordo com Hackman e Lawler (1971), as Dimensões Essenciais do Trabalho são variáveis passíveis de mensuração que apresentam as seguintes definições:

- Variedade: o quanto é exigido que os trabalhadores apresentem uma variedade de operações em seu trabalho e/ou utilizem uma variedade de equipamentos e procedimentos em seu trabalho;

- Autonomia: o quanto os trabalhadores possuem de autoridade para programar as suas atividades, podendo escolher o equipamentos que serão utilizados e decidir os procedimentos que serão empregados;

- Identidade da Tarefa: o quanto os trabalhadores realizam atividades completas em seu trabalho e podem identificar claramente o resultado de seus esforços;

- Feedback: o quanto os trabalhadores recebem informações sobre o seu desempenho no trabalho e/ou o quão corretamente este vem sendo realizado.

Foi convencionado que o nível máximo de motivação é obtido somente quando um trabalho apresenta, simultaneamente, o escore máximo em todas as Dimensões Essenciais do Trabalho. Nesse contexto, para que um trabalho seja Revista Produção Online, v.10, n.3, p. 670-697, set., 2010 
motivador, a percepção do trabalhador com relação às cinco Dimensões Essenciais do Trabalho deve ser positiva.

Entretanto, foi constatado a necessidade de determinar se todas as dimensões deveriam apresentar escores elevados para que 0 trabalhador apresentasse elevada motivação. Nessa perspectiva, o nível de motivação foi correlacionado com as quadro Dimensões Essenciais do Trabalho de três diferentes formas:

a) Somando-se os escores das quatro dimensões;

b) Cada dimensão sendo tratada independentemente;

c) Através do produto dos escores das quatro dimensões.

Os resultados da pesquisa empírica realizada por Hackman e Lawler (1971) demonstraram que o nível de satisfação diminui significativamente quando o escore de uma das dimensões é relativamente baixo em relação às demais dimensões. Fato que não ocorre quando os escores das quatro dimensões são reduzidos na mesma proporção. Assim sendo, as quatro Dimensões Essenciais do Trabalho possuem pesos igualmente distribuídos na determinação da motivação proporcionada pelo trabalho, sendo que a motivação poderia ser calculada através da seguinte fórmula:

\section{Variedade X Autonomia X Identidade da Tarefa X Feedback}

Através da aplicação do instrumento, Hackman e Lawler constataram que, para um trabalho proporcionar elevado nível de motivação, as quatro Dimensões Essenciais do Trabalho devem apresentar escores moderadamente elevados.

Para a determinação do nível motivacional proporcionado pelo trabalho, foi utilizado um questionário composto por 12 questões, seccionado em duas seções. A primeira seção contempla uma avaliação direta do trabalho através de questões fechadas, com respostas baseadas em uma escala de Likert de sete alternativas. Cada questão possui sua própria escala, de forma que o indicador 1 representa 0 pior resultado, o indicador 4 representa o resultado intermediário, e o indicador 7 representa o melhor resultado. 
Cada dimensão é contemplada com uma única questão. A seção 1 do instrumento proposto por Hackman e Lawler (1971) apresenta as seguintes questões:

\begin{tabular}{|l|}
\multicolumn{1}{|c|}{ SEÇÃO 1 (Hackman e Lawler, 1971) } \\
\hline 1) Qual é o nível de variedade presente no seu trabalho? \\
\hline 2) Qual é o nível de autonomia existente em seu trabalho; o quanto você pode decidir de \\
que forma será realizado o seu trabalho? \\
\hline 3) O quanto você desenvolve em seu trabalho, atividades que são iniciadas e terminadas \\
por você (ao invés de realizar tarefas que são terminadas por outras pessoas)? \\
\hline 4) O quanto seu trabalho fornece informações que permitem avaliar a qualidade das \\
atividades que você executa?
\end{tabular}

Quadro 1 - Seção 1 de Hackman e Lawler

Fonte: Adaptado de Hackman e Lawler (1971)

A segunda seção faz menção a uma série de aspectos relacionados às quatro Dimensões Essenciais do Trabalho, sendo que o respondente deve assinalar, em uma escala de Likert de sete alternativas, o quanto cada atributo está presente em seu trabalho. O indicador 1 representa "nada ou minimamente", o indicador 4 representa "moderadamente" e o indicador 7 representa "freqüentemente". Os indicadores 1 e 7 sempre representam, respectivamente, o pior e o melhor resultado.

Cada dimensão apresenta dois itens. A seção 2 do instrumento proposto por Hackman e Lawler (1971) apresenta as seguintes questões:

5) A oportunidade para pensar e agir independentemente.

6) A oportunidade de descobrir o quão corretamente eu venho realizando o meu trabalho.

7) A oportunidade de terminar as atividades que eu iniciei.

8) A percepção de que o meu trabalho está sendo realizado de forma boa ou ruim.

9) A oportunidade de realizar uma variedade de atividades.

10) A oportunidade de realizar atividades do inicio ao fim, isto é, realizar uma atividade completa.

11) A liberdade para realizar as atividades da forma que eu quero.

12) A quantidade de variedade presente em meu trabalho.

Quadro 2 - Seção 2 de Hackman e Lawler

Fonte: Adaptado de Hackman e Lawler (1971)

No que diz respeito às Dimensões Essenciais do Trabalho, as questões que compõem cada uma destas, no instrumento de Hackman e Lawler (1971), são:

- Variedade: Q1, Q9 e Q12;

- Autonomia: Q2, Q5 e Q11; 
- Identidade: Q3, Q7 e Q10;

- Feedback: Q4, Q6 e Q8.

Mesmo que Hackman e Lawler (1971) afirmem que para que o nível de motivação ocasionado pelo trabalho seja alto deve haver equilíbrio entre as quatro Dimensões Essenciais do Trabalho, estes não propõem um escore padronizado para o cálculo do nível de motivação proporcionado pelo trabalho.

\section{MODELO DE HACKMAN E OLDHAM}

Em um estudo subsequente à Hackman e Lawler (1971), Hackman e Oldham (1974) propuseram uma reformulação do modelo anterior. O novo modelo considera que o trabalho apresenta cinco dimensões essenciais, ao invés de quatro, como proposto no instrumento precedente. A dimensão adicional é chamada de Significância da Tarefa. As Dimensões Essenciais do Trabalho propostas por Hackman e Oldham (1975) são:

- Variedade da Tarefa: o quanto um emprego requer variedade atividades na execução do trabalho, utilização de diferentes habilidades e talentos do trabalhador;

- Identidade da Tarefa: o quanto é exigido que os trabalhadores realizem atividades completas, isto é, atividades que possuem um início em um fim lógico;

- Significância da Tarefa: o quanto o resultado de um emprego impacta na vida ou no trabalho de outras pessoas, tanta na própria organização ou externamente a esta;

- Autonomia: o quanto um trabalho fornece liberdade, independência e privacidade, de forma que o trabalhador possa programar o seu trabalho e determinar os procedimentos que serão empregados para realizá-lo;

- Feedback: grau com o qual a execução das atividades laborais proporcionam ao trabalhador a retroação de informações precisas e claras sobre o seu desempenho no trabalho. 
Assim como no modelo de Hackman e Lawler (1971), o modelo proposto por Hackman e Oldham (1974) não trata as Dimensões Essenciais do Trabalho isoladamente e não fundamenta a motivação proporcionada pelo trabalho através da média aritmética das mesmas, mas sim, através do produto das dimensões. Entretanto, o cálculo do nível de motivação do trabalho de ambos os estudo diferese devido ao fato de Hackman e Oldham (1974) terem atribuído pesos diferenciados às dimensões.

Através da média aritmética entre os escores das dimensões Variedade da Tarefa, Identidade da Tarefa e Significância da Tarefa, seguido de uma multiplicação pelos escores das dimensões Autonomia e Feedback, obtém-se um escore que determina o nível de motivação proporcionado por um trabalho. Este escore é denominado Potencial Motivador do Trabalho.

(Variedade da Tarefa + Identidade da Tarefa + Significado da Tarefa) $X$ Autonomia X Feedback

Nesse novo modelo, o cálculo é realizado por uma medida geométrica, onde, diferentemente do modelo de Hackman e Lawler (1971), as dimensões Variedade da Tarefa, Identidade da Tarefa e Significância da Tarefa, possuem peso menor do que as dimensões Autonomia e Feedback.

Seguindo o modelo de Hackman e Lawler (1971), o questionário para determinação do Potencial Motivador do Trabalho é composto duas seções, sendo este acrescido de três itens que contemplam a nova dimensão, a Significância da Tarefa. Assim, o instrumento proposto por Hackman e Oldham possui 15 questões.

Da mesma forma que a Seção 1 do modelo de Hackman e Lawler (1971), esta primeira seção contempla uma avaliação direta do trabalho através de questões fechadas, com respostas baseadas em uma escala de Likert de sete alternativas. A escala de resposta é diferenciada em todas as questões, sendo que as alternativas fazem menção direta à dimensão do trabalho abordada em cada questão. Em todas as questões, indicador 1 representa o pior resultado, o indicador 4 representa 0 resultado intermediário, e o indicador 7 representa o melhor resultado. 
Cada dimensão do trabalho é contemplada com uma questão, fazendo com que a Seção 1 do instrumento proposto por Hackman e Oldham (1974) apresente a seguinte configuração:

\section{SEÇÃO 1 (Hackman e Oldham, 1974)}

Q1) Qual é o nível de autonomia existente no seu trabalho? Isso é, até que ponto the é permitido decidir a maneira de realizar suas tarefas?

Q2) O quanto você desenvolve em seu trabalho atividades do inicio ao fim? Isso é, uma atividade que possui inicio e fim óbvio? Ou é apenas uma etapa de uma atividade, finalizada por outras pessoas ou máquinas?

Q3) Qual o nível de variedade presente no seu trabalho? Isso é, até que ponto o trabalho lhe exige realizar tarefas diferentes, que requerem habilidades distintas?

Q4) De um modo geral, o quão significante ou importante é o seu trabalho? Isso é, o resultado do seu trabalho influencia na vida ou no bem-estar de outras pessoas?

Q5) O quanto você recebe informações sobre o seu desempenho no trabalho? Isso é, você tem conhecimento se o seu trabalho tem sido bem executado-através de algum "feedback" que colegas de trabalho ou supervisores fornecem?

\section{Quadro 3 - Seção 1 de Hackman e Oldham}

Fonte: Adaptado de Hackman e Oldham (1974)

A segunda seção do instrumento é composta por afirmações relacionadas às cinco Dimensões Essenciais do Trabalho, sendo que o respondente deve assinalar, em uma escala de Likert de sete alternativas, qual é o nível de exatidão de cada uma das afirmações, ou seja, o quanto estas estão corretas. O indicador 1 representa "discordância total", o indicador 4 representa "indecisão" e o indicador 7 representa "concordância total".

Ao contrário das Seções 1 e 2 de Hackman e Lawler (1971) e da Seção 1 de Hackman e Oldham (1974), os indicadores 1 e 7 nem sempre representam os respectivos pior e melhor resultado. Nessa seção há questões onde a escala de resposta é invertida. Ou seja, o indicador 1 representa a melhor resposta, enquanto o indicador 7 representa a pior resposta.

Cada dimensão é representada por dois itens, de forma que um item de cada dimensão está disposto em escala de respostas normal e o outro item está disposto em escala de respostas invertida. A seção 2 do instrumento proposto por Hackman e Oldham (1974) apresenta, com os itens cuja escala de respostas é invertida grafados em itálico, os seguintes itens: 


\section{SEÇÃO 2 (Hackman e Oldham, 1974)}

Q6) Meu trabalho exige que eu utilize diversas habilidades complexas ou de alto-nível.

Q7) Meu trabalho é organizado de forma a não me possibilitar a realização de atividades completas, do inicio ao fim.

Q8) O simples fato de realizar o trabalho me proporciona muitas chances para compreender o quão bem eu venho o fazendo.

Q9) O trabalho é bastante extenso e repetitivo.

Q10) A qualidade com a qual realizo o meu trabalho pode afetar muitas pessoas. Q11) Em meu trabalho não tenho nenhuma oportunidade de tomar iniciativas ou decisões.

Q12) Em meu trabalho tenho a oportunidade de terminar as atividades que iniciei.

Q13) Meu trabalho fornece poucas informações sobre o desempenho com o qual eu o realizo.

Q14) Em meu trabalho possuo independência e liberdade para realizá-lo da forma que eu preferir.

Q15) Meu trabalho em si não é muito importante ou significante para a empresa de forma global.

Quadro 4 - Seção 2 de Hackman e Oldham

Fonte: Adaptado de Hackman e Oldham (1974)

Quanto às Dimensões Essenciais do Trabalho, as questões que compõem cada uma destas, no instrumento de Hackman e Oldham (1974), são:

- Variedade da Tarefa: Q3, Q6 e Q9;

- Identidade da Tarefa: Q2, Q7 e Q12;

- Significância da Tarefa: Q4, Q10 e Q15;

- Autonomia: Q1, Q11 e Q14;

- Feedback: Q5, Q8 e Q13.

Fica evidenciado que o modelo de Hackman e Oldham (1974) teve embasamento no modelo anterior proposto por Hackman e Lawler (1971). As alterações realizadas por Hackman e Oldham (1974) sobre o modelo de Hackman e Lawler (1971) podem ser visualizadas no quadro 5: 


\begin{tabular}{|c|c|c|}
\hline DIMENSÕES & HACKMAN E LAWLER (1971) & HACKMAN E OLDHAM (1974) \\
\hline \multirow{3}{*}{ Variedade } & $\begin{array}{l}\text { Qual é o nível de variedade presente no seu } \\
\text { trabalho? }\end{array}$ & $\begin{array}{l}\text { Qual é o nível de variedade presente no seu } \\
\text { trabalho? Isso é, até que ponto o trabalho lhe } \\
\text { exige realizar tarefas diferentes, que requerem } \\
\text { habilidades distintas? }\end{array}$ \\
\hline & $\begin{array}{l}\text { A quantidade de variedade presente em meu } \\
\text { trabalho. }\end{array}$ & $\begin{array}{l}\text { Meu trabalho exige que eu utilize diversas } \\
\text { habilidades complexas ou de alto-nível. }\end{array}$ \\
\hline & $\begin{array}{l}\text { A oportunidade de realizar uma variedade de } \\
\text { atividades. }\end{array}$ & O trabalho é bastante extenso e repetitivo. \\
\hline \multirow{3}{*}{ Autonomia } & $\begin{array}{l}\text { Qual é o nível de autonomia existente em seu } \\
\text { trabalho; o quanto você pode decidir de que forma } \\
\text { será realizado o seu trabalho? }\end{array}$ & $\begin{array}{l}\text { Qual é o nível de autonomia existente no seu } \\
\text { trabalho? Isso é, até que ponto Ihe é permitido } \\
\text { decidir a maneira de realizar suas tarefas? }\end{array}$ \\
\hline & $\begin{array}{l}\text { A liberdade para realizar as atividades da forma } \\
\text { que eu quero. }\end{array}$ & $\begin{array}{l}\text { Em meu trabalho possuo independência e } \\
\text { liberdade para realizá-lo da forma que eu preferir. }\end{array}$ \\
\hline & $\begin{array}{l}\text { A oportunidade para pensar e agir } \\
\text { independentemente. }\end{array}$ & $\begin{array}{l}\text { Em meu trabalho não tenho nenhuma } \\
\text { oportunidade de tomar iniciativas ou decisões. }\end{array}$ \\
\hline \multirow{3}{*}{ Identidade } & $\begin{array}{l}\text { O quanto você desenvolve em seu trabalho, } \\
\text { atividades que são iniciadas e terminadas por } \\
\text { você (ao invés de realizar tarefas que são } \\
\text { terminadas por outras pessoas)? }\end{array}$ & $\begin{array}{l}\text { O quanto você desenvolve em seu trabalho } \\
\text { atividades do inicio ao fim? Isso é, uma atividade } \\
\text { que possui inicio e fim óbvio? Ou é apenas uma } \\
\text { etapa de uma atividade, finalizada por outras } \\
\text { pessoas ou máquinas? }\end{array}$ \\
\hline & $\begin{array}{l}\text { A oportunidade de terminar as atividades que eu } \\
\text { iniciei. }\end{array}$ & $\begin{array}{l}\text { Em meu trabalho tenho a oportunidade de } \\
\text { terminar as atividades que iniciei. }\end{array}$ \\
\hline & $\begin{array}{l}\text { A oportunidade de realizar atividades do inicio ao } \\
\text { fim, isto é, realizar uma atividade completa. }\end{array}$ & $\begin{array}{l}\text { Meu trabalho é organizado de forma a não me } \\
\text { possibilitar a realização de atividades completas, } \\
\text { do inicio ao fim. }\end{array}$ \\
\hline \multirow{3}{*}{ Feedback } & $\begin{array}{l}\text { O quanto seu trabalho fornece informações que } \\
\text { permitem avaliar a qualidade das atividades que } \\
\text { você executa? }\end{array}$ & $\begin{array}{l}\text { O quanto você recebe informações sobre o seu } \\
\text { desempenho no trabalho? Isso é, você tem } \\
\text { conhecimento se o seu trabalho tem sido bem } \\
\text { executado-através de algum "feedback" que } \\
\text { colegas de trabalho ou supervisores fornecem? }\end{array}$ \\
\hline & $\begin{array}{l}\text { A oportunidade de descobrir o quão corretamente } \\
\text { eu venho realizando o meu trabalho. }\end{array}$ & $\begin{array}{l}\text { O simples fato de realizar o trabalho me } \\
\text { proporciona muitas chances para compreender o } \\
\text { quão bem eu venho o fazendo. }\end{array}$ \\
\hline & $\begin{array}{l}\text { A percepção de que o meu trabalho está sendo } \\
\text { realizado de forma boa ou ruim. }\end{array}$ & $\begin{array}{l}\text { Meu trabalho fornece poucas informações sobre } \\
\text { o desempenho com o qual eu o realizo. }\end{array}$ \\
\hline \multirow{3}{*}{ Significância } & & $\begin{array}{l}\text { De um modo geral, o quão significativo ou } \\
\text { importante é o seu trabalho? Isto é, o resultado } \\
\text { do seu trabalho influencia na vida ou no bem- } \\
\text { estar de outras pessoas? }\end{array}$ \\
\hline & & $\begin{array}{l}\text { A qualidade com que realizo o meu trabalho pode } \\
\text { afetar muitas pessoas. }\end{array}$ \\
\hline & & $\begin{array}{l}\text { Meu trabalho, em si, não é muito importante ou } \\
\text { significativo para a empresa de forma global. }\end{array}$ \\
\hline
\end{tabular}

Quadro 5: Dimensões do trabalho de Hackman e Lawler e Hackman e Oldham Fonte: Adaptado de Hackman e Lawler (1971) e Hackman e Oldham (1974). 
As questões presentes na Seção 1 no modelo de Hackman e Lawler (1971) tornam-se mais específicas e diretas no modelo da Hackman e Oldham (1974).

$\mathrm{Na}$ Seção 2, percebe-se que os dois itens relacionados à mesma dimensão, são muito semelhantes. $\mathrm{Na}$ tentativa de diferi-los, sem que estes assumam sentidos distintos, Hackman e Oldham (1974) propuseram a inversão da escala de respostas em um dos itens de cada dimensão. Ainda na Seção 2, enquanto Hackman e Lawler (1971) questionam o quanto cada um dos aspectos mencionados está presente no trabalho, Hackman e Oldham (1974) preferem transformar tais aspectos em afirmações, questionando o quanto estas são verdadeiras, do ponto de vista do respondente.

Em se tratando de uma adaptação de um estudo anterior, a principal contribuição de Hackman e Oldham (1974) foi a determinação de parâmetros para se calcular o nível de motivação provinda do trabalho. Nível esse que foi representado pelo escore batizado de Potencial Motivador do Trabalho.

\section{METODO}

Com o intuito de disponibilizar uma ferramenta para determinação do nível de motivação ocasionado pelo trabalho, este estudo pautou-se na tradução para a língua portuguesa do instrumento de Hackman e Oldham (1974). Também foi realizada uma adaptação do instrumento para a cultura brasileira, de forma que este possa ser facilmente interpretado, sem que haja divergências com relação à versão original do instrumento.

O processo de tradução e adaptação cultural do instrumento de avaliação do Potencial Motivador do Trabalho envolveu uma equipe multidisciplinar composta por quatro pesquisadores da área da Qualidade de Vida - dois mestres e dois doutores -, dois tradutores bilíngues e um filólogo da língua portuguesa, possuindo estes 0 título de mestre. Para a tradução e adaptação cultural foram utilizados os seguintes procedimentos:

1) Tradução literal do instrumento, realizada por um pesquisador bilíngue com conhecimentos aprofundados sobre o instrumento em exame; 
2) Revisão ortográfica do instrumento traduzido, realizada por um filólogo da língua portuguesa;

3) Adaptação cultural do linguajar do instrumento traduzido para a população objeto de estudo do instrumento, em que um grupo 30 trabalhadores de cargos diferenciados respondeu a versão provisória do instrumento, comentando as dificuldades de interpretação encontradas, tal qual proferindo sugestões para a supressão de tais imbróglios;

4) Reformulação do instrumento a partir das sugestões provenientes do grupo de trabalhadores que responderam a versão piloto do instrumento;

5) Confronto entre $o$ instrumento traduzido e o instrumento em seu idioma original, realizado primeiramente por um tradutor bilíngue independente, que não participou das etapas anteriores, e, posteriormente, em conjunto por toda a equipe participante do projeto.

Seguindo o instrumento original proposto por Hackman e Oldham (1974), as questões da Seção 1 foram dispostas na forma interrogativa, possuindo escalas diferenciadas entre si, e atribuições somente aos valores mínimo, médio e máximo, conforme demonstra a Figura 2:

1) Qual é nível de autonomia existente em seu trabalho? Isto é, até que ponto the é permitido decidir a maneira de realizar suas tarefas?

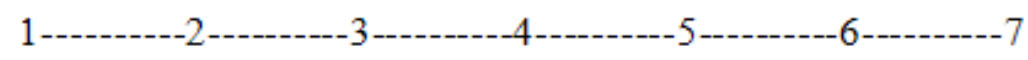

$\begin{array}{ll}\text { Muito pouca } & \text { Autonomia moderada; } \\ \text { autonomia; meu } & \text { muitos aspectos são } \\ \text { trabalho não me } & \text { padronizados e não } \\ \text { permite decidir como e } & \text { estão sob meu controle, } \\ \text { quando realizar as } & \text { mas eu posso tomar } \\ \text { tarefas. } & \text { algumas decisões. }\end{array}$

Muita autonomia; meu trabalho me permite total responsabilidade para decidir como e quando fazê-lo.

Figura 2 - Exemplo de questão e escala de respostas da Seção 1 Fonte: Autoria própria

As questões da Seção 2 também seguiram o instrumento original de Hackman e Oldham (1974), sendo dispostas na forma de afirmações. A escala de respostas é a mesma para todas as questões desta seção, conforme o exemplo contido na figura 3 : 
6) Meu trabalho exige que eu utilize diversas habilidades complexas ou de alto-nível.

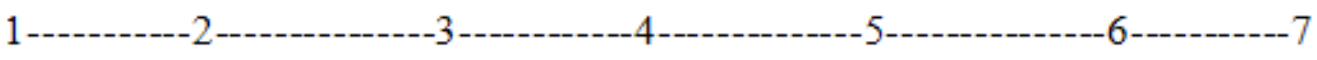

\begin{tabular}{|c|c|c|c|c|c|c|}
\hline $\begin{array}{c}\text { Muito } \\
\text { incorreta }\end{array}$ & $\begin{array}{c}\text { Geralmente } \\
\text { incorreta }\end{array}$ & $\begin{array}{c}\text { Ligeiramente } \\
\text { incorreta }\end{array}$ & Indeciso & $\begin{array}{c}\text { Ligeiramente } \\
\text { correta }\end{array}$ & $\begin{array}{c}\text { Geralmente } \\
\text { correta }\end{array}$ & $\begin{array}{c}\text { Muito } \\
\text { correta }\end{array}$ \\
\hline
\end{tabular}

Figura 3 - Exemplo de questão e escala de respostas da Seção 2

Fonte: Autoria própria

Frente aos procedimentos utilizados, a escala de respostas do tipo Likert de sete alternativas foi mantida. A ordem das questões também não foi alterada. As questões cuja escala de respostas é invertida, não sofreram alteração. A preservação das características do instrumento original faz com que o cálculo do escore do Potencial Motivador do Trabalho seja realizado exatamente conforme fora proposto por Hackman e Oldham (1974).

Para garantir a fidedignidade do instrumento em exame, mais especificamente com relação à verificação da consistência interna do instrumento, utilizou-se da aplicação do coeficiente alfa de Cronbach. Desenvolvido por Lee Cronbach em 1951, o coeficiente alfa de Cronbach é uma ferramenta estatística que avalia a confiabilidade através da consistência interna de um questionário. Para a utilização do coeficiente alfa de Cronbach, é requisito que todos os itens do instrumento utilizem a mesma escala de medição (FREITAS; RODRIGUES, 2005).

A análise de consistência interna é pautada na correlação do itens de um mesmo constructo entre si e na correlação de cada item com o escore total deste constructo. É desejável que os itens se apresentem moderadamente correlacionados entre si, e, também, que cada item apresente correlação com o escore total do constructo.

O alfa de Cronbach é obtido a partir da variância dos componentes individuais e da variância da soma dos componentes de cada avaliado, buscando investigar as possíveis relações entre os itens (CRONBACH, 1951). Dessa forma, as variáveis utilizadas no cálculo do coeficiente de Cronbach são: o número de questões do instrumento $(K)$, a variância de cada questão $\left(S_{i}^{2}\right)$ e a variância total do instrumento $\left(S_{t}^{2}\right)$. O coeficiente alfa de Cronbach é calculado através da seguinte equação: 


$$
\alpha=\left(\frac{K}{K-1}\right) *\left(1-\frac{\sum_{i=1}^{k} S_{i}^{2}}{S_{t}^{2}}\right)
$$

Não existe um consenso quanto à avaliação do coeficiente alfa de Cronbach, cabendo ao pesquisador decidir qual o valor mínimo de consistência interna aceitável para o seu respectivo instrumento (CRONBACH, 1951).

No presente estudo utilizou-se- da classificação proposta por Freitas e Rodrigues (2005), que apresenta a seguinte escala para análise do coeficiente alfa de Cronbach:

Tabela 1: Escala de consistência interna do coeficiente alfa de Cronbach

\begin{tabular}{ll}
\hline \multicolumn{1}{c}{ Valor de $\alpha$} & \multicolumn{1}{c}{ Consistência } \\
\hline$\alpha \leq 0,30$ & Muito baixa \\
$0,30<\alpha \leq 0,60$ & Baixa \\
$0,60<\alpha \leq 0,75$ & Moderada \\
$0,75<\alpha \leq 0,90$ & Alta \\
$\alpha>0,90$ & Muito alta \\
\hline
\end{tabular}

Fonte: Freitas e Rodrigues (2005)

Foi realizada uma aplicação do instrumento em 96 colaboradores vinculados a três empresas de ramos distintos, em que obtivera-se o resultado do coeficiente alfa de Cronbach do instrumento de $\alpha=0,8992$, podendo-se afirmar, com base na classificação proposta por Freitas e Rodrigues (2005), que o instrumento em exame apresenta elevada consistência interna.

\subsection{Cálculo dos escores}

O cálculo dos escores das dimensões do trabalho é realizado através da média aritmética simples entre as três questões que compõem cada dimensão. É preciso inverter as questões cuja escala de respostas é invertida (Q7, Q9, Q11, Q13 e Q15). Dessa forma, os escores das Dimensões Essenciais do Trabalho são obtidos através das seguintes fórmulas: 


\begin{tabular}{|l|c|}
\hline \multicolumn{1}{|c|}{ DIMENSÃO } & CÁLCULO DO ESCORE \\
\hline Variedade da Tarefa & $\frac{Q_{3}+Q_{6}+\downarrow Q_{9}}{3}$ \\
\hline Identidade da Tarefa & $\frac{Q_{2}+\downarrow Q_{7}+Q_{12}}{3}$ \\
\hline Significância da & $\frac{Q_{4}+Q_{10}+\downarrow Q_{15}}{3}$ \\
Tarefa & $\frac{Q_{1}+\downarrow Q_{11}+Q_{14}}{3}$ \\
\hline Autonomia & $\frac{Q_{5}+Q_{8}+\downarrow Q_{13}}{3}$ \\
\hline Feedback & \\
\hline
\end{tabular}

Quadro 6: Cálculo dos escores das Dimensões Essenciais do Trabalho Fonte: Autoria própria

onde $\downarrow$ representa a inversão da escala.

Quanto ao Potencial Motivador do Trabalho (PMT), representado por:

(Variedade da Tarefa + Identidade da Tarefa + Significado da Tarefa) X Autonomia X Feedback

3

este pode ser calculado pela seguinte fórmula:

$P M T=\frac{\frac{Q_{3}+Q_{6}+\downarrow Q_{9}}{3}+\frac{Q_{2}+\downarrow Q_{7}+Q_{12}}{3}+\frac{Q_{4}+Q_{10}+\downarrow Q_{15}}{3}}{3} * \frac{Q_{1}+\downarrow Q_{11}+Q_{14}}{3} * \frac{Q_{5}+Q_{8}+\downarrow Q_{13}}{3}$

(2)

Desenvolvendo a equação utilizando os escores máximos em todas as questões, tem-se:

$$
P M T=\frac{\frac{7+7+\downarrow 1}{3}+\frac{7+\downarrow 1+7}{3}+\frac{7+7+\downarrow 1}{3}}{3} * \frac{7+\downarrow 1+7}{3} * \frac{7+7+\downarrow 1}{3}
$$


Para realizar a inversão da escala foi utilizada a seguinte equação:
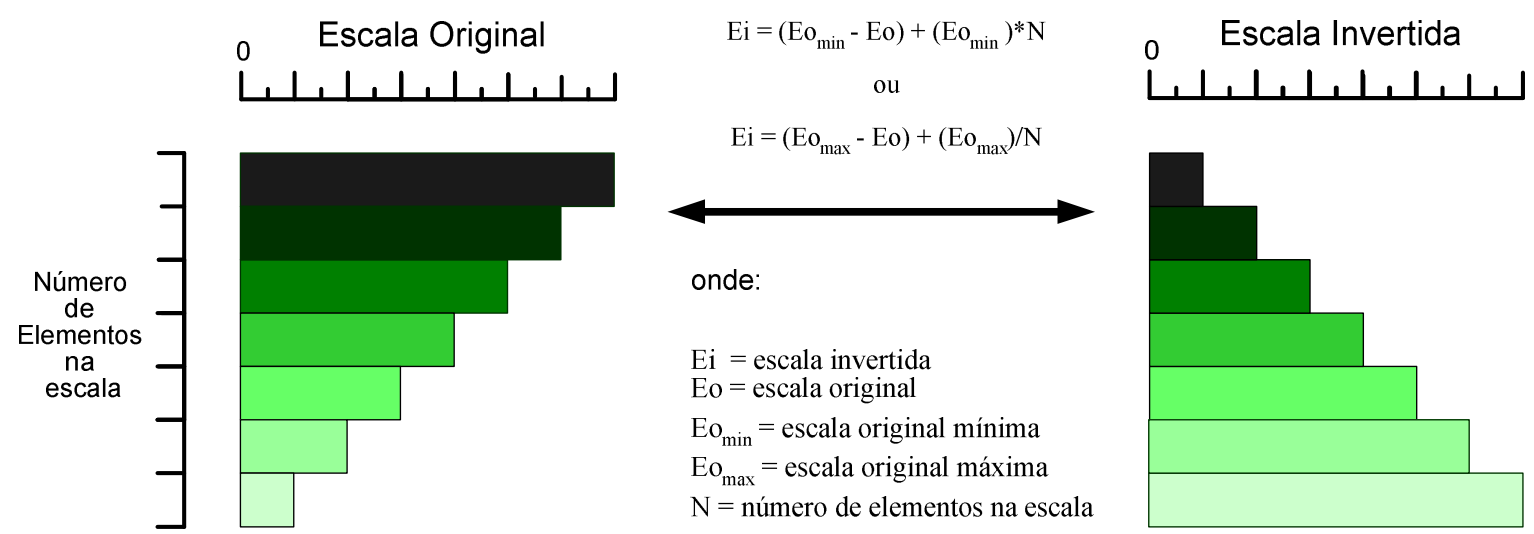

Figura 4 - Equação para Inversão de Escala Fonte: Autoria própria

Conforme ilustrado na figura anterior, após a inversão da escala, os itens invertidos passam a assumir os seguintes valores:

\begin{tabular}{|c|c|}
\hline $\begin{array}{c}\text { Escala } \\
\text { original }\end{array}$ & $\begin{array}{c}\text { Escala } \\
\text { invertida }\end{array}$ \\
\hline 1 & 7 \\
\hline 2 & 6 \\
\hline 3 & 5 \\
\hline 4 & 4 \\
\hline 5 & 3 \\
\hline 6 & 2 \\
\hline 7 & 1 \\
\hline
\end{tabular}

Quadro 7 - Resultados da inversão de escala

Fonte: Autoria própria

Retomando ao cálculo do Potencial Motivador do Trabalho, após as devidas inversões, o escore máximo que esta variável pode assumir é 343, enquanto o escore mínimo é 1. Portanto, a pontuação do Potencial Motivador do Trabalho varia entre 1 e 343, sendo que, de acordo com Hackman e Oldham (1974), é utilizado o valor 125 como ponto de referência. Os valores iguais ou superiores a 125 são considerados satisfatórios, enquanto os valores inferiores a 125 são considerados insatisfatórios.

Em se tratando de uma medida geométrica que engloba três valores (Variedade da Tarefa + Identidade da Tarefa + Significância da Tarefa; Autonomia; Feedback), para se obter, na escala original do instrumento, o valor que representa 0 
ponto de referência, basta extrair a raiz cúbica do valor de referência (125). Tal cálculo resulta no valor 5 .

Dessa forma, obtém-se que, utilizando a escala original do instrumento (de 1 a 7), os valores 1, 2, 3 e 4 enquadram-se como insatisfatórios, enquanto os valores 5,6 e 7 enquadram-se como satisfatórios.

A utilização de uma escala geométrica pode gerar dúvidas quanto a sua interpretação. As controvérsias ocasionadas pela escala geométrica se devem ao fato de que, na medida em que os escores médios das Dimensões Essenciais do Trabalho aumentam em uma proporção aritmética, o escore do Potencial Motivador do Trabalho aumenta em uma proporção geométrica.

$\mathrm{Na}$ perspectiva de tornar facilitada a utilização do presente instrumento, é proposta uma classificação através de uma escala centesimal. Para representar a pontuação em uma escala de 0 a 100, ao invés da escala que varia entre 1 e 343, uma vez que o escore do Potencial Motivador do Trabalho resulta de uma função geométrica, o presente estudo adotou a seguinte equação:

$(\sqrt[3]{P M T})-1) * \frac{100}{7-1}(4)$

Seguindo o cálculo proposto anteriormente, a conversão das pontuações do escore do Potencial Motivador do Trabalho resulta no quadro a seguir:

\begin{tabular}{|c|c|r|l|}
\hline \multirow{2}{*}{ Likert } & \multicolumn{3}{|c|}{ PMT } \\
\cline { 2 - 3 } & Escore & Centesimal & Classificação \\
\hline 1 & 1 & 0,00 & \\
\hline 2 & 8 & 16,67 & \multirow{2}{*}{ Insatisfatório } \\
\hline 3 & 27 & 33,33 & \\
\hline 4 & 64 & 50,00 & \\
\hline 5 & 125 & 66,67 & \multirow{2}{*}{ Satisfatório } \\
\hline 6 & 216 & 83,33 & \multirow{2}{*}{} \\
\hline 7 & 343 & 100,00 & \\
\hline
\end{tabular}

Quadro 8 - Relação de Equivalência entre as escalas

Fonte: Autoria própria

As relações entre as escalas podem ser representadas a partir da figura seguinte: 


\section{Escalas}

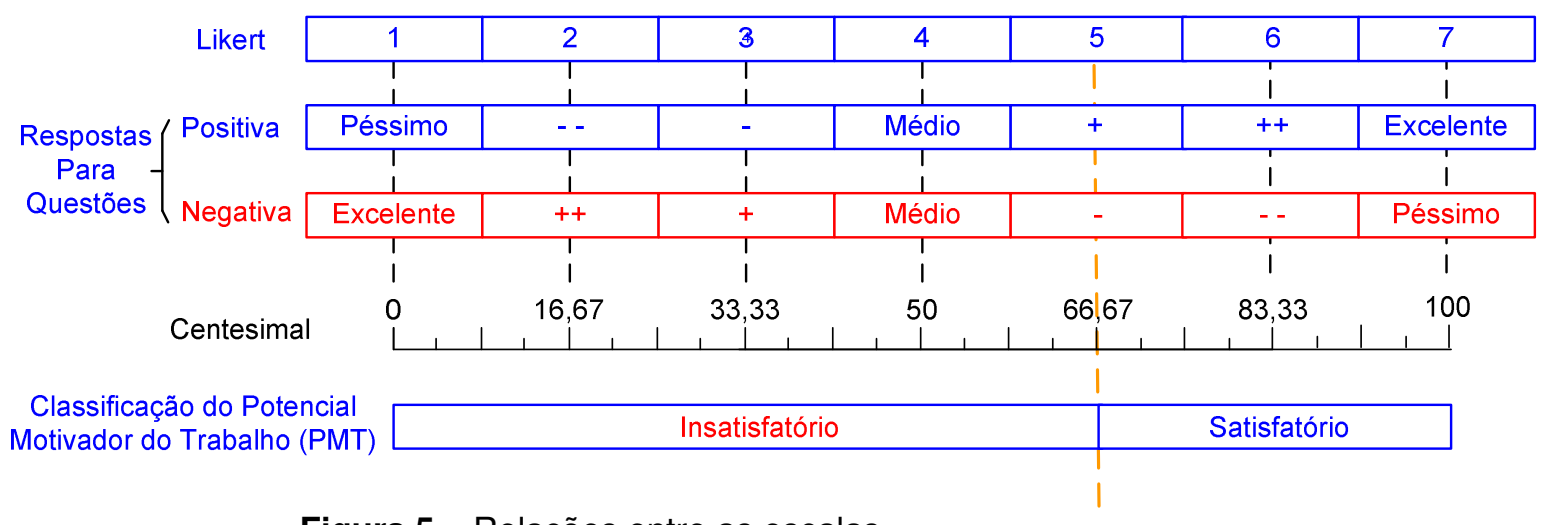

Figura 5 - Relações entre as escalas Fonte: Autoria própria

Seguindo a classificação proposta no presente estudo, o ponto de referência, originalmente adotado como o valor 125 em uma escala de 343 pontos, passa a ser o valor 66,67 na escala centesimal. Sob esse enfoque, pode-se afirmar que os resultados que apresentem um nível motivacional igual ou superior a $66,67 \%$ podem ser considerados satisfatórios, enquanto os resultados que apresentem um nível motivacional inferior a $66,67 \%$ podem ser considerados insatisfatórios.

Para o cálculo dos escores do instrumento em pauta foi construída uma ferramenta através do software Microsoft Excel que realiza o cálculo dos escores e a estatística descritiva do instrumento desenvolvido no presente estudo. Na referida ferramenta, todos os cálculos e gráficos são realizados de forma automatizada, bastando o pesquisador tabular os dados coletados nos locais especificados. A utilização do Microsoft Excel justifica-se no fato de este ser amplamente difundido e utilizado por pesquisadores de todas as áreas do conhecimento.

O download da versão completa do instrumento e a ferramenta para o cálculo dos escores das aplicações deste pode ser realizado através do link: http://www.brunopedroso.com.br/pmt.html.

\section{CONSIDERAÇÕES FINAIS}

A necessidade de um indicador para avaliar a Qualidade de Vida no Trabalho suscitou a criação de diversos modelos teóricos quantitativos e qualitativos para mensurar o nível com o qual um trabalho pode proporcionar motivação ao 
colaborador. Dentre estes, o modelo de Hackman e Oldham (1974). Embasado em cinco Dimensões Essenciais do Trabalho (Variedade da Tarefa, Identidade da Tarefa, Significância da Tarefa, Autonomia e Feedback), esse índice recebeu a denominação de Potencial Motivador do Trabalho.

O modelo em exame partiu do instrumento proposto por Hackman e Lawler (1971), constituído pelas dimensões Variedade, Autonomia, Identidade e Feedback. Hackman e Oldham (1974) propuseram uma reformulação deste modelo. O novo modelo se constituiu por meio do acréscimo da dimensão Significância e da atribuição de pesos diferenciados às dimensões.

Mesmo se tratando de um modelo amplamente utilizado, a difusão do modelo de Hackman e Oldham ainda não transpôs a barreira idiomática lusófona. Tal fato motivou a disponibilização do instrumento no idioma português. O processo de tradução e adaptação cultural do instrumento de Hackman e Oldham foi realizado a partir de uma equipe multidisciplinar, envolvendo pesquisadores e profissionais da área de lingüística. Os procedimentos utilizados foram: tradução, correção ortográfica, adaptação para a cultura local, e, finalmente, a conferência com a versão original.

As características originais do instrumento foram preservadas. $O$ total de 15 itens na forma de questões fechadas e a escala de respostas do tipo Likert de sete alternativas foram mantidas. Os resultados são, primeiramente, calculados através da escala geométrica original do instrumento (1 a 343), fazendo com que as aplicações do instrumento traduzido e adaptado culturalmente possam ser comparadas com o instrumento em seu idioma vernáculo.

Com o intuito de facilitar a interpretação dos resultados do escore do Potencial Motivador do Trabalho, os resultados também são expressos através de uma escala centesimal. Dessa forma o resultado passa a ser apresentado através de uma variável percentual. Esta adaptação torna o escore do Potencial Motivador do Trabalho passível de comparação com os escores das Dimensões Essenciais do Trabalho, além de permitir que esse se inter-relacione com outros instrumentos. 


\section{REFERÊNCIAS}

CHANG JÚNIOR, J.; ALBUQUERQUE, L. G. Comprometimento organizacional: uma abordagem holística e simultânea dos determinantes envolvidos no processo. Revista de Administração Mackenzie, São Paulo, v. 3, n. 2, p. 13-38, 2002.

CRONBACH, L. J. Coefficient alpha and the internal structure of tests.

Psychometrika, Greensboro, NC, v. 16, n. 3, p. 297-334, set. 1951.

DAVIS, K.; NEWSTROM, J. W. Comportamento humano no trabalho: uma abordagem organizacional, v. 2. 3. ed. São Paulo: Pioneira, 2004.

FERNANDES, E. C. Qualidade de vida no trabalho: como medir para melhorar. Salvador: Casa da Qualidade, 1996.

FREITAS, A. L. P., RODRIGUES, S. G. A avaliação da confiabilidade de questionário: uma análise utilizando o coeficiente alfa de Cronbach. In: SIMPÓSIO DE ENGENHARIA DE PRODUÇÃO, 12., 2005, Bauru. Anais... Bauru: UNESP, 2005.

FRIDAY, S. S.; FRIDAY, E. Racioethnic perceptions of job characteristics and job satisfaction. Journal of Management Development, Bingley, v. 22, n. 5, p. 426-442, 2003.

GABRIS, G. T.; IHRKE, D.M. Does performance appraisal contribute to heightened levels of employee burnout? The results of one study, Public Personnel Management, v. 30, n. 2, p.157-171, mar. 2001.

HACKMAN, J. R.; LAWLER, E. E. Employee reactions to job characteristics. Journal of applied psychology monograph, East Lansing, v. 55, n. 3, p. 259-286, jun. 1971.

HACKMAN, J. R.; OLDHAM, G. R. The job diagnostic survey: an instrument for the diagnosis of jobs and the evaluation of job redesign projects. Technical report n. 4, Department of Administrative Sciences of Yale University, may, 1974.

HACKMAN, J. R.; OLDHAM, G. R. Development of the job diagnostic survey. Journal of applied psychology, East Lansing, v. 60, n. 2, p. 159-170, apr. 1975.

LAWRENCE, R. M. The application of Hackman and Oldham's job characteristic model to perceptions community music school faculty have towards their job. 2001. $167 \mathrm{f}$. Thesis (PhD in Musical Education) - UNT College of Music, University of North Texas, Denton.

LEE-ROSS, D. Perceived job characteristics and internal work motivation: an exploratory cross-cultural analysis of the motivational antecedents of hotel workers in Mauritius and Australia. Journal of Management Development, Bingley v. 24, n. 3, p. 253-266, 2005. 
TODD, S. Y.; KENT, A. Direct and indirect effects of task characteristics on organizational citizenship behavior. North American Journal of Psychology, v. 8, n. 2, 253-268, 2006.

TOLFO, S. R.; PICCININI, V. C. As melhores empresas para trabalhar no Brasil e a qualidade de vida no trabalho: disjunções entre a teoria e a prática. Revista de Administração Contemporânea, Curitiba, v. 5, n. 1, p. 165-193, jan./abr. 2001.

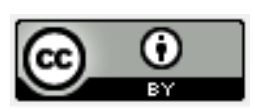

Artigo recebido em 13/01/2010 e aceito para publicação em 03/08/2010. 


\section{ANEXO 1 - PESQUISA DE DIAGNÓSTICO DO TRABALHO}

O presente questionário objetiva determinar os pontos em que o seu trabalho pode ser melhorado, através da obtenção de informações a respeito da reação das pessoas nos mais variados tipos de trabalho.

Nas próximas páginas você encontrará perguntas variadas sobre seu emprego. Ao inicio de cada sessão estão as instruções correspondentes a tal bloco de perguntas. Leia as questões cuidadosamente. O preenchimento do questionário não deve demorar mais do que 10 minutos.

As questões foram elaboradas para obter a sua percepção sobre o seu trabalho e como você reage diante disso. Não existe nenhuma "pegadinha". Suas respostas serão mantidas em completo sigilo. Por favor, responda todas as questões o mais honestamente possível.

Obrigado pela sua colaboração.

\section{SEÇÃO 1}

Nesta seção você deve descrever o seu trabalho, da forma mais objetiva o possível. Não utilize esta seção para expressar o quanto você gosta ou não gosta do seu emprego. Procure descrever seu trabalho da forma mais precisa e objetiva que você conseguir.

\section{Circule o número que corresponde à opção que melhor descreve o seu trabalho:}

1) Qual é o nível de autonomia existente em seu trabalho? Isto é, até que ponto lhe é permitido decidir a maneira de realizar suas tarefas?

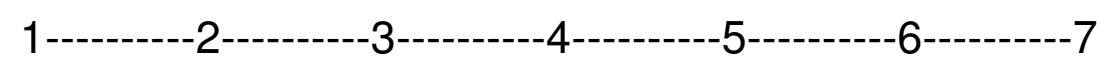

$\begin{array}{ll}\text { Muito pouca } & \text { Autonomia } \\ \text { autonomia; meu } & \text { moderada; muitos } \\ \text { trabalho não me } & \text { aspectos são } \\ \text { permite decidir como } & \text { padronizados e não } \\ \text { e quando realizar as } & \text { estão sob meu } \\ \text { tarefas. } & \text { controle, mas eu } \\ & \text { posso tomar } \\ & \text { algumas decisões. }\end{array}$
Muita autonomia; meu trabalho me permite total responsabilidade para decidir como e quando fazê-lo.

2) Você desenvolve em seu trabalho atividades do início ao fim? Ou apenas uma das etapas, de uma atividade finalizada por outras pessoas ou máquinas?

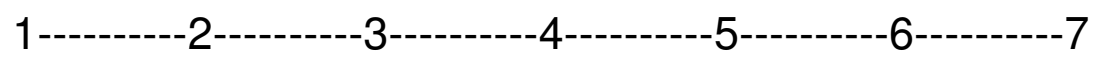




$\begin{array}{lll}\begin{array}{l}\text { Meu trabalho é } \\ \text { somente uma }\end{array} & \begin{array}{l}\text { Meu trabalho é uma } \\ \text { parcela moderada do } \\ \text { pequena parte do }\end{array} & \begin{array}{l}\text { Meu trabalho } \\ \text { trabalho global; }\end{array} \\ \begin{array}{l}\text { envolve terminar } \\ \text { trabalho global; o }\end{array} & \begin{array}{l}\text { minha contribuição } \\ \text { resultado das minhas }\end{array} & \text { que iniciei; os } \\ \text { atividades não pode } & \text { resultado final. } & \text { resultados das } \\ \text { ser visto no serviço } & & \text { minhas atividades } \\ \text { ou produto final. } & & \text { são facilmente vistos } \\ & & \text { no serviço ou }\end{array}$

3) Qual o nível de variedade presente em seu trabalho? Isto é, até que ponto o trabalho Ihe exige realizar tarefas diferentes, que requerem habilidades distintas?

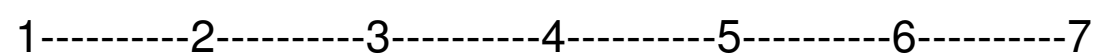

$\begin{array}{lll}\text { Muito pouca } & \text { Variedade } & \text { Muita variedade; o } \\ \text { variedade; o trabalho } & \text { moderada. } & \text { trabalho requer que } \\ \text { requer que eu faça } & & \text { eu faça muitas } \\ \text { as mesmas } & \text { atividades diferentes, } \\ \text { atividades rotineiras } & \text { usando várias } \\ \text { inúmeras vezes. } & \text { habilidades e } \\ & \text { talentos distintos. }\end{array}$

4) De um modo geral, o quão significativo ou importante é o seu trabalho? Isto é, o resultado do seu trabalho influencia na vida ou no bem-estar de outras pessoas?

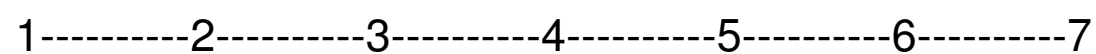

\begin{tabular}{|c|c|c|}
\hline $\begin{array}{l}\text { Não muito } \\
\text { significativo; os } \\
\text { resultados de meu } \\
\text { trabalho não } \\
\text { aparentam } \\
\text { influenciar outras } \\
\text { pessoas }\end{array}$ & $\begin{array}{l}\text { Moderadamente } \\
\text { significativo. }\end{array}$ & $\begin{array}{l}\text { Altamente } \\
\text { significativo; os } \\
\text { resultados de meu } \\
\text { trabalho podem } \\
\text { influenciar outras } \\
\text { pessoas de diversas } \\
\text { maneiras. }\end{array}$ \\
\hline
\end{tabular}

5) Você recebe informações sobre o seu desempenho no trabalho, através de colegas ou supervisores?

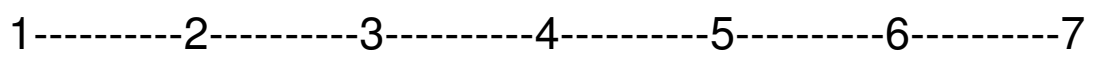

$\begin{array}{ll}\text { Muito pouco; o } & \begin{array}{l}\text { Moderadamente; } \\ \text { algumas vezes } \\ \text { trabalho é }\end{array} \\ \text { organizado de forma } & \text { recebo feedback, } \\ \text { que eu jamais } & \text { outras vezes não. } \\ \text { descubro o meu } & \\ \text { desempenho. } & \end{array}$


Muito; o trabalho é

organizado de forma

que constantemente

eu obtenho feedback

sobre o meu

desempenho. 


\section{SEÇÃO 2}

Nesta seção você deve indicar como você se sente em relação ao seu trabalho. Cada uma das afirmações abaixo diz respeito a alguma característica do seu trabalho. Você deve indicar seu sentimento pessoal sobre os aspectos do seu trabalho, assinalando o quanto você concorda com cada uma das afirmações.

\section{Circule o número que corresponde ao quão correta, com relação à descrição do seu trabalho, você considera cada uma das afirmações:}

6) Meu trabalho exige que eu utilize diversas habilidades complexas ou de alto-nível.

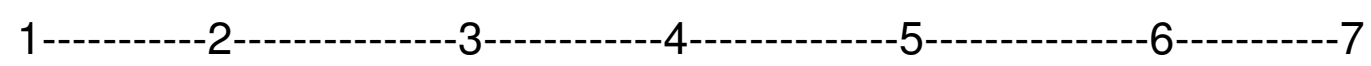

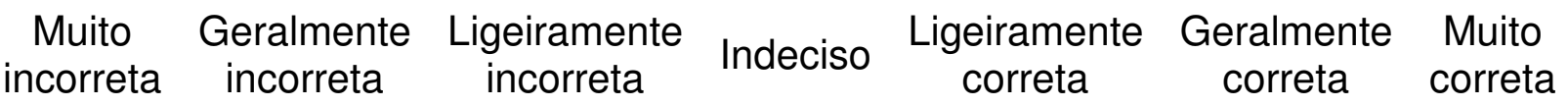

7) Meu trabalho é organizado de forma a não me possibilitar a realização de atividades completas, do início ao fim.

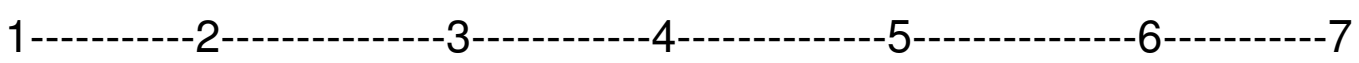

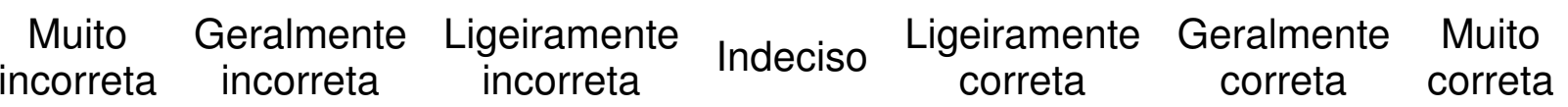

8) O trabalho que executo oportuniza-me avaliar meu desempenho.

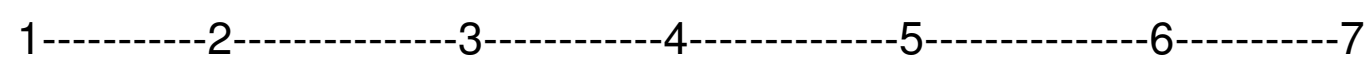

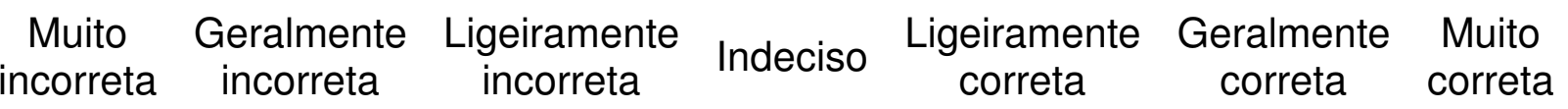

9) O trabalho é bastante extenso e repetitivo.

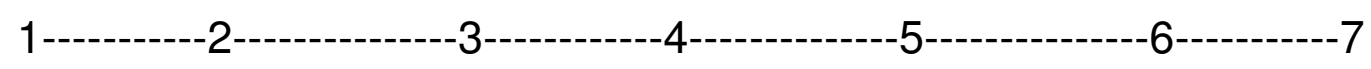

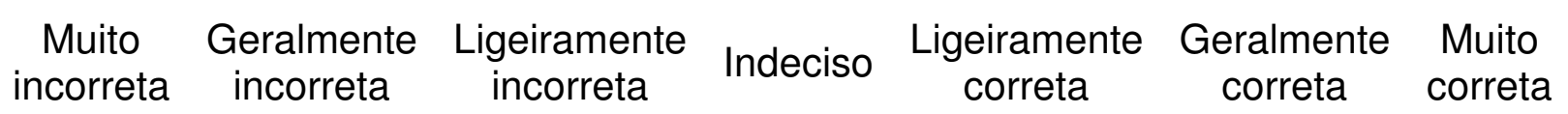

10) A qualidade com que realizo o meu trabalho pode afetar muitas pessoas. 


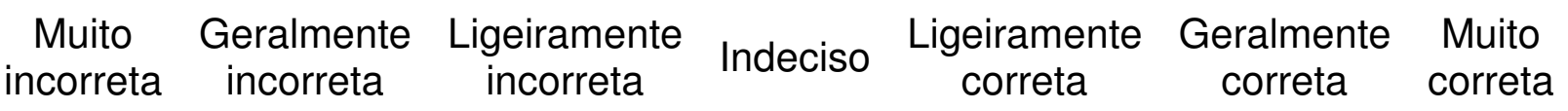

11) Em meu trabalho não tenho nenhuma oportunidade de tomar iniciativas ou decisões.

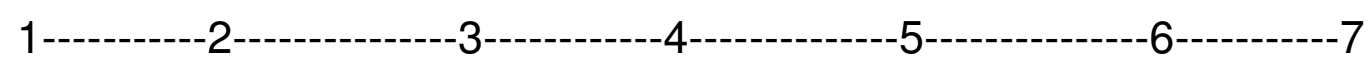

$\begin{array}{cccc}\text { Muito } & \begin{array}{c}\text { Geralmente } \\ \text { incorreta } \\ \text { incorreta }\end{array} & \begin{array}{c}\text { Ligeiramente } \\ \text { incorreta }\end{array} & \text { Indeciso } \\ \begin{array}{c}\text { Ligeiramente } \\ \text { correta }\end{array} & \begin{array}{c}\text { Geralmente } \\ \text { correta }\end{array} & \text { Muito } \\ \text { correta }\end{array}$ 12) Em meu trabalho, tenho a oportunidade de terminar as atividades que iniciei.

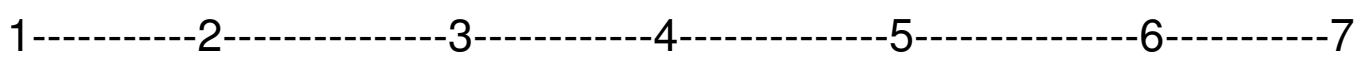

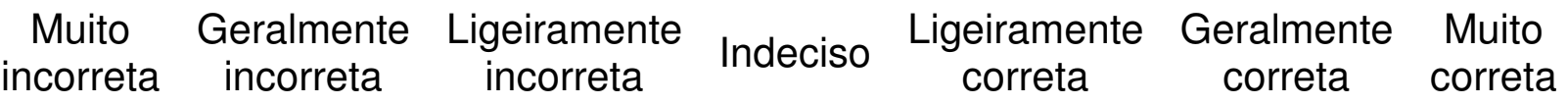

13) Meu trabalho fornece poucas informações sobre o meu desempenho.

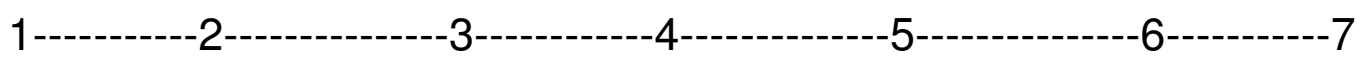

Muito Geralmente Ligeiramente Indeciso Ligeiramente Geralmente Muito incorreta incorreta incorreta Indeciso correta correta correta

14) Em meu trabalho, possuo independência e liberdade para realizá-lo da forma que eu preferir.

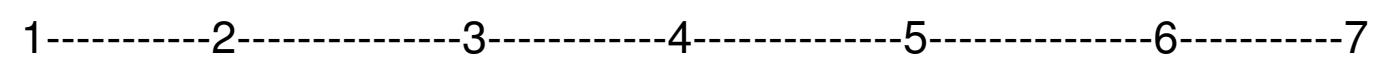

$\begin{array}{cccc}\text { Muito } & \begin{array}{c}\text { Geralmente } \\ \text { incorreta }\end{array} \text { incorreta } & \begin{array}{c}\text { Ligeiramente } \\ \text { incorreta }\end{array} & \text { Indeciso } \\ \text { correta } & \begin{array}{c}\text { Ligeiramente } \\ \text { corralmente }\end{array} & \text { Muito } \\ \text { correta }\end{array}$

15) Meu trabalho, em si, não é muito importante ou significativo para a empresa de forma global.

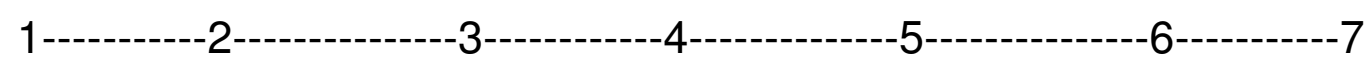

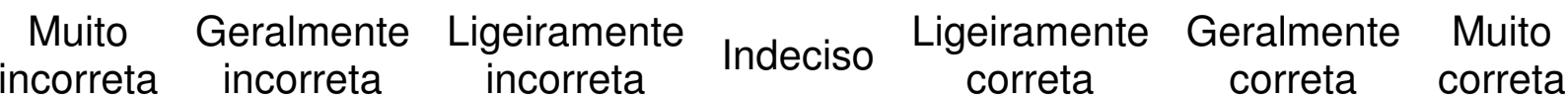

